\title{
A Genetic-Fuzzy System for Modelling of Selected Processes in Diesel Engine Fuelled by Biofuels
}

\author{
Michał Kekez and Leszek Radziszewski \\ Kielce University of Technology \\ Poland
}

\section{Introduction}

The work of diesel engine fuelled by various fuels can be modelled by the methods based on the first law of thermodynamics (Rychter \& Teodorczyk, 2006), or the CFD (computational fluid dynamics) methods (Amsden, 1997). However, all these methods have some deficiencies. The first group of methods can give results which have insufficient accuracy at some ranges of engine working cycle. The second group of methods produces models which cannot be easily applied to real-time control of a diesel engine. The concise and fast model of a diesel engine working cycle should be found. The methods which belong to the group of computational intelligence (CI) methods are also used for modelling selected aspects of engine work (Kalogirou, 2003) and many results are encouraging. However, the pressure course in cylinder or injection pipe was rarely modelled by CI methods. In the next sections we present the single model of cylinder pressure and injection pressure in a diesel engine fuelled by RME (rapeseed methyl esters) or its blends with diesel oil. The model was created by means of the GFSm system proposed by the authors. The methodology that allows the extension of the created model for other fuels is also presented. The obtained model can be applied to diagnostic and control of a diesel engine. One of the advantages of the proposed method is that the model is built for a one given engine and therefore describes its work with good accuracy.

\section{Test bench}

Experimental research and necessary measurements of cylinder pressure, injector pressure and injector needle lift curves were carried out on test bench, which consisted of a three cylinder diesel engine, water brake and control panel. There were four measurement chains (Fig. 1). The engine was fuelled by diesel oil, RME (methyl esters of rapeseed oil), and its blends. Cylinder pressure values and injection pressure values were recorded every $1.406^{\circ}$ CA (exactly 512 measurements for one working cycle of four-stroke engine). At each measurement point, defined by crankshaft angle, values of parameters were recorded for 50 consecutive working cycles and later averaged. This methodology was used for all tested fuels. The experiments were conducted when engine operated at full-load and part-load conditions, with crankshaft rotational speeds of 1000, 1200, 1400, 1600, 1800, and $2000 \mathrm{rpm}$ (revolutions per minute). 


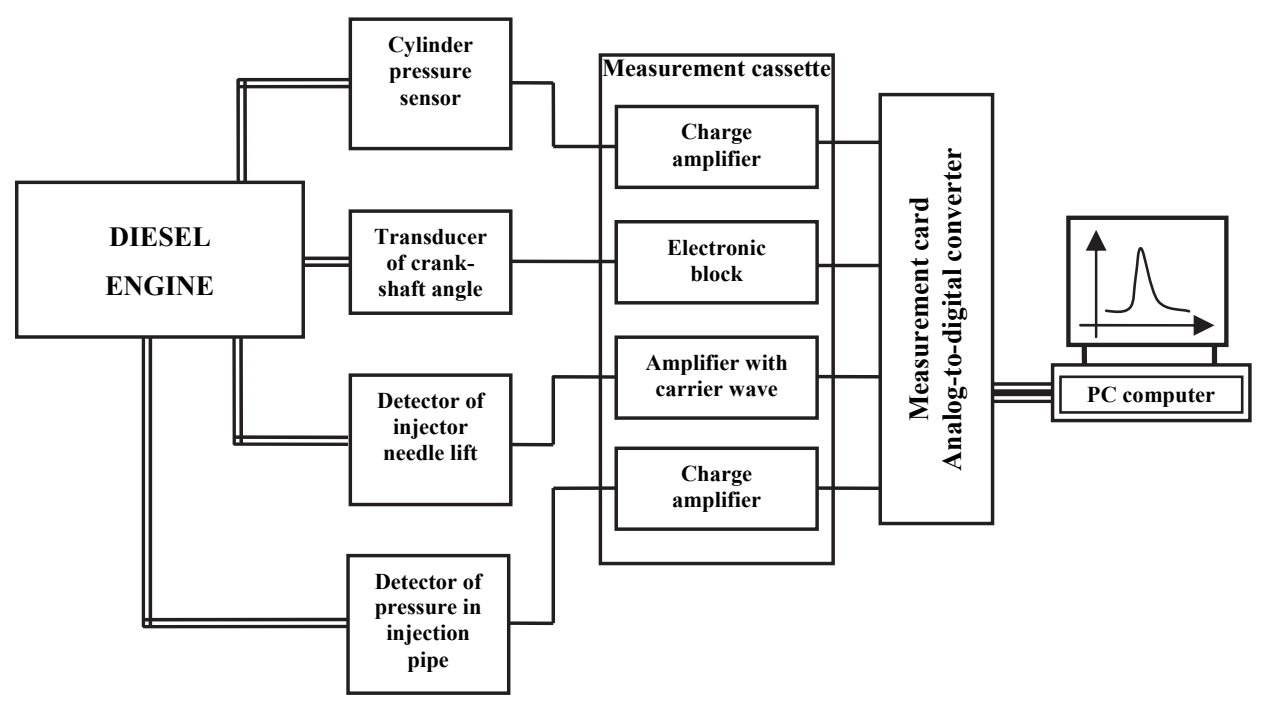

Fig. 1. The scheme of measurement chains (Ambrozik et al., 2010)

\section{Results of experimental research}

The measured values, when engine was fuelled by RME, are presented in Figure 2. Cylinder pressure (Fig.2a) in the range below $351{ }^{\circ} \mathrm{CA}$ is almost identical for all tested rotational speeds. Pressure starts to increase rapidly when it reaches 3 to $4 \mathrm{MPa}$, and when crankshaft rotation angle lies between $351^{\circ}$ (for speed of $1000 \mathrm{rpm}$ ) and $357^{\circ} \mathrm{CA}$ (for speed of $2000 \mathrm{rpm}$ ). When rotational speed of crankshaft increases, the maximum value of pressure decreases from 8.5 to $8 \mathrm{MPa}$. The first derivative of pressure with respect to crankshaft angle decreases from 0.92 to $0.68 \mathrm{MPa} /{ }^{\circ} \mathrm{CA}$ with the increase of rotational speed from 1400 to $2000 \mathrm{rpm}$.

Injection pressure (Fig. 2b) in the range below $335{ }^{\circ} \mathrm{CA}$ is almost identical for all tested rotational speeds. Pressure increases rapidly in the range of about 335 to $340{ }^{\circ} \mathrm{CA}$, but when reaches about $20 \mathrm{MPa}$ (injector opening pressure), its increase becomes much slower or it starts to decrease. Maximum pressure value increases with the increase of rotational speed. The area below the pressure curve (which is related to amount of fuel) changes from 382 $\mathrm{MPa} \cdot{ }^{\circ} \mathrm{CA}$ at $1000 \mathrm{rpm}$ to $492 \mathrm{MPa} \cdot{ }^{\circ} \mathrm{CA}$ at $2000 \mathrm{rpm}$.

\section{Genetic-fuzzy system GFSm}

The proposed GFSm system (Kekez, 2008; Radziszewski \& Kekez, 2010) belongs to the group of genetic-fuzzy rule-based systems (Cordon et al., 2001), i.e. fuzzy systems which use genetic algorithm to improve or create a set of rules. There are at least four approaches in these systems: Pittsburgh (Smith, 1983) and Michigan (Holland, 1976) approaches, iterative rule learning (Cordon et al., 2001), and co-evolutionary approach (Regattieri Delgado et al., 2004). GFSm uses genetic learning of the whole knowledge base, not only membership functions of fuzzy set, and uses modified Pittsburgh approach (with advanced encoding, or, in other words, special arrangement of data in a chromosome). The Pittsburgh approach 


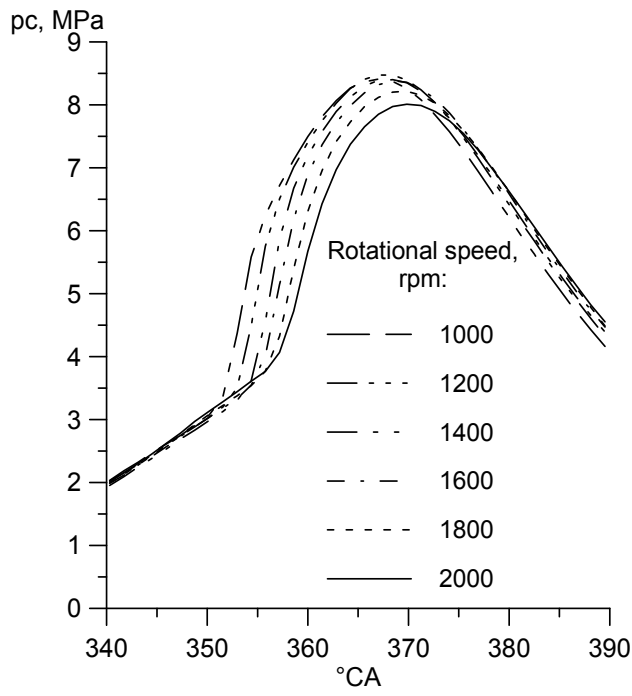

(a)

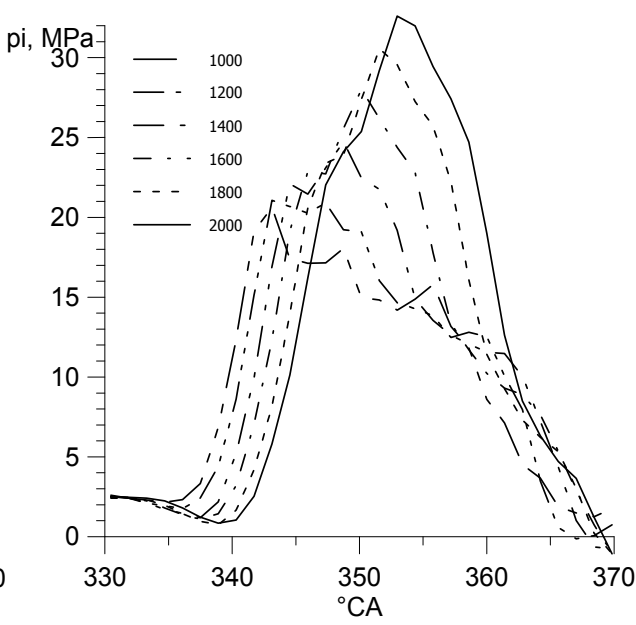

(b)

Fig. 2. The curves of $p_{c}$ cylinder pressure $(a)$ and $p_{i}$ injection pressure $(b)$ in function of crankshaft angle in the engine fuelled by RME at rotational speeds 1000, 1200, 1400, 1600, 1800 and $2000 \mathrm{rpm}$

offers wide exploration of the solution space, but has several drawbacks, which were avoided by using the above-mentioned encoding in GFSm system.

\subsection{Fuzzy systems}

For the fuzzy system having $m$ input variables, $x_{i}$, and one output variable, $y$, the fuzzy rule has at most $m$ conditions (or premises) of the form $x_{i}$ IS $A_{i}$, where $A_{i}$ denotes a fuzzy set. The consequent of the rule ( $y$ IS $\left.B_{j}\right)$ is placed after "THEN" in the rule. The fuzzy rule has the form $\operatorname{IF}\left[\left(x_{1} \operatorname{IS} A_{1}\right) \operatorname{AND}\left(x_{2} \operatorname{IS} A_{2}\right) \operatorname{AND} \ldots \operatorname{AND}\left(x_{m} \operatorname{IS} A_{m}\right)\right] \operatorname{THEN}\left(y \operatorname{IS} B_{j}\right)$ and is called the Mamdani-type rule. In the Takagi-Sugeno-type of fuzzy rule, the consequent has the form $y=w_{0}+w_{1} \cdot x_{1}+w_{2} \cdot x_{2}+\ldots+w_{m} \cdot x_{m}$, where $w_{i}$ are constants. A set of fuzzy rules (also known as a rule base or a rule set) together with definitions of membership functions of fuzzy sets is called the knowledge base of a fuzzy system. Each fuzzy set is described by its membership function, which usually has two parameters, $a$ and $b$, called center and width, respectively; see e.g. equations (3) and (4) in Section 5. For reasoning in fuzzy systems, the defuzzification method must be also defined.

\subsection{Genetic algorithm (GA) used in GFSm}

Genetic algorithms (GAs) search for optimal solution. Solution parameters are encoded in a binary string called a chromosome. Specifically in GFSm, a solution refers to a fuzzy system. The number of chromosomes is called a population size $q$. Fragments of a chromosome are called genes (implemented as binary strings or single bits). The GA searches for optimal solution by exchanging fragments of chromosomes (using so-called crossover operator) and by randomly changing some bits in chromosome (using so-called mutation operator). The 
quality of each solution encoded by one chromosome is evaluated before the application of the above-mentioned operators. If GA uses the elitist strategy, the best chromosome at each stage is copied to the next stage without crossover or mutation. Initial set of chromosomes is called an initial population. The initial population in GFSm is built by the following routine:

1. The maximum number of fuzzy sets describing the $i$-th input of the fuzzy system $(i=1, \ldots, m)$ is set as a GFSm input parameter $j_{\max i}$.

2. For each input, create two fuzzy sets with sigmoidal membership functions (Eq. 2), and $j_{\max i}-2$ fuzzy sets with Gaussian membership functions (Eq. 3); for each fuzzy set, create randomly two parameters $(a$ and $b$ ) of these functions.

3. Create 10 fuzzy sets with triangular membership functions (Eq. 4), which uniformly divide the range of output values.

4. Given all these fuzzy sets, build a set of rules by using the (Wang \& Mendel, 1992) method for Mamdani-type systems, or by using the (Abonyi et al., 2002) method for Takagi-Sugeno systems

5. Repeat steps 2-4 for all $q$ fuzzy systems.

\subsection{Encoding of information for GA used in GFSm}

The idea of advanced encoding in GFSm system, proposed in (Kekez, 2008), means the fragmentation of rules. All information in the chromosome is grouped by the number of input to which it refers. In a chromosome, all pieces of rules regarding given input are located just after the definitions of fuzzy sets for this input (Fig. 3).



Fig. 3. Encoding of information in a chromosome, used in GFSm system (Kekez, 2008)

The last part of a chromosome stores the information about which rules are present ("active") in a rule base of a fuzzy system. The "validity" bits $v f, v p, v r_{1}, v r_{2}, \ldots, v r_{R}$ (Fig. 3) allow to dynamically activate or deactivate a fuzzy set, a premise in a rule, and a whole rule, respectively. A chromosome has fixed length, but number of rules can vary in the range $\langle 0, R\rangle$, because each $v r_{r}$ bit $(r=1 \ldots R)$ activates or deactivates $r$-th rule. The maximum number of rules, $R$, is calculated during the creation of initial population. A rule need not to contain the premises $\left(x_{i}\right.$ IS $A_{i j}$ ) regarding all inputs because each $v p$ bit includes or excludes a premise in a rule. Similarly, the total number of fuzzy sets describing $i$-th input varies from 0 to $j_{\max i}$ because of $v f$ bits. The $j_{\max i}$ value is set by the user before the start of the GFSm system, as described in Section 4.2. A chromosome also contains either the definitions 
of fuzzy sets $B_{j}$, which describe system output (in Mamdani-type fuzzy systems), or $w_{i}$ parameters of the consequent of the rule (in Takagi-Sugeno-type systems).

The proposed idea of information encoding allows processing of high-dimensional data, and retains the connection between the definition of a given fuzzy set and its references in the rules. Like in Michigan approach, the crossover operator connects fragments of rules. These fragments come from rules which have the identical consequent.

\section{Model of pressures in diesel engine}

The results of experiments for two selected rotational speeds (1200 and $1800 \mathrm{rpm}$ ) when engine was fuelled by diesel oil were used as a training dataset for GFSm system. Each row in the training dataset consisted of $\left(x_{1}, x_{2}, x_{3}, y\right)$ values. The $x_{1}$ was a crankshaft rotation angle $\alpha$, and $x_{2}$ was not a rotational speed $n$, but the time (in milliseconds) elapsed since the moment when crankshaft rotation angle was $335^{\circ} \mathrm{CA}$ :

$$
x_{2}=\left\{\begin{array}{cc}
0 & \text { for } \alpha \leq 335 \\
\frac{(\alpha-335) \cdot 60}{n \cdot 360} \cdot 1000 & \text { for } \alpha>335
\end{array}\right.
$$

The $x_{3}$ denotes the type of pressure: it was equal 1 for injection pressure and 0 for cylinder pressure. The $y$ was the pressure value for a given $x_{1}, x_{2}$, and $x_{3}$.

The GFSm system was run twice with the following options:

- $\quad$ type of the fuzzy system: Mamdani,

- population size: 50,

- probability of crossover: 0.77 .

In the first run we obtained 12 rules containing " $x_{3}$ is $A_{3,1}$ " condition (regarding cylinder pressure), and in the second run we also obtained 12 rules with " $x_{3}$ is $A_{3,2}$ " condition (regarding injection pressure).

By using GFSm system, we obtained one model of pressure courses consisting of 24 Mamdani-type fuzzy rules (Fig. 4).

In Fig. 4 , the notations $(\mathrm{S}, a, b),(\mathrm{M}, a, b)$, and $(\mathrm{T}, a, b)$, where $a$ and $b$ are constants, identify fuzzy sets defined by a sigmoidal

$$
\mu_{A}(x, a, b)=\frac{1}{1+e^{b \cdot(x-a)}}, b \neq 0
$$

Gaussian

$$
\mu_{A}(x, a, b)=e^{-\left(\frac{x-a}{b}\right)^{2}}
$$

or triangular

$$
\mu_{A}(x, a, b)=\left\{\begin{array}{cl}
0 & \text { for } x \leq a-b \\
\frac{x-a+b}{b} & \text { for } a-b \leq x \leq a \\
\frac{a+b-x}{b} & \text { for } a \leq x \leq a+b \\
0 & \text { for } x \geq a+b
\end{array}\right.
$$


membership functions, respectively. The $A_{3,1}$ and $A_{3,2}$ refer to singleton fuzzy sets which pertain to cylinder pressure $\left(p_{\mathrm{c}}\right)$ or injection pressure $\left(p_{\mathrm{i}}\right)$, respectively.

The operation of the model is depicted in Fig. 5, where "knowledge base" refers to membership functions of fuzzy sets and set of rules shown in Fig. 4.

if $x_{1}$ is $(M, 416.34,23.23)$ and $x_{3}$ is $A_{3,1}$ then $y$ is $(T, 0.11,0.97)$

if $x_{1}$ is $(M, 292.50,38.50)$ and $x_{3}$ is $A_{3,1}$ then $y$ is $(T, 0.11,0.97)$

if $x_{1}$ is $(M, 200.29,47.34)$ and $x_{3}$ is $A_{3,1}$ then $y$ is $(T, 0.11,0.97)$

if $x_{1}$ is $(S, 433.52,-0.07)$ and $x_{3}$ is $A_{3,1}$ then $y$ is $(T, 0.11,0.97)$

if $x_{1}$ is $(M, 412.02,93.24)$ and $x_{2}$ is $(M, 26.05,10.48)$ and $x_{3}$ is $A_{3,1}$ then $y$ is $(T, 1.06,0.97)$

if $x_{1}$ is $(M, 445.80,35.32)$ and $x_{3}$ is $A_{3,1}$ then $y$ is $(T, 1.06,0.97)$

if $x_{1}$ is $(M, 346.29,7.52)$ and $x_{2}$ is $(M, 6.77,4.43)$ and $x_{3}$ is $A_{3,1}$ then $y$ is $(T, 1.06,0.97)$

if $x_{1}$ is $(M, 180.37,137.34)$ and $x_{2}$ is $(M, 1.08,0.46)$ and $x_{3}$ is $A_{3,1}$ then $y$ is $(T, 2.52,0.97)$

if $x_{1}$ is $(M, 393.65,11.07)$ and $x_{3}$ is $A_{3,1}$ then $y$ is $(T, 2.53,0.97)$

if $x_{1}$ is $(M, 364.22,38.06)$ and $x_{2}$ is $(M, 26.05,10.48)$ and $x_{3}$ is $A_{3,1}$ then $y$ is $(T, 7.89,0.97)$

if $x_{1}$ is $(M, 364.22,38.06)$ and $x_{2}$ is $(M, 6.46,3.76)$ and $x_{3}$ is $A_{3,1}$ then $y$ is $(T, 8.79,0.97)$

if $x_{1}$ is $(M, 333.05,121.68)$ and $x_{2}$ is $(M, 3.91,1.49)$ and $x_{3}$ is $A_{3,1}$ then $y$ is $(T, 8.79,0.97)$

if $x_{1}$ is $(S, 363.69,-0.72)$ and $x_{3}$ is $A_{3,2}$ then $y$ is $(T,-0.90,3.34)$

if $x_{1}$ is $(M, 352.12,15.31)$ and $x_{2}$ is $(S, 0.38,4.90)$ and $x_{3}$ is $A_{3,2}$ then $y$ is $(T,-0.90,3.34)$

if $x_{1}$ is $(S, 335.39,0.21)$ and $x_{3}$ is $A_{3,2}$ then $y$ is $(T, 3.28,3.34)$

if $x_{1}$ is $(M, 362.23,2.46)$ and $x_{2}$ is $(M, 2.54,0.50)$ and $x_{3}$ is $A_{3,2}$ then $y$ is $(T, 4.59,3.34)$

if $x_{1}$ is $(M, 362.23,2.46)$ and $x_{2}$ is $(S, 3.01,-10.24)$ and $x_{3}$ is $A_{3,2}$ then $y$ is $(T, 10.81,3.34)$

if $x_{1}$ is $(M, 357.54,7.13)$ and $x_{2}$ is $(M, 2.94,0.66)$ and $x_{3}$ is $A_{3,2}$ then $y$ is $(T, 12.69,3.34)$

if $x_{1}$ is $(M, 350.37,11.20)$ and $x_{2}$ is $(M, 2.94,0.66)$ and $x_{3}$ is $A_{3,2}$ then $y$ is $(T, 14.99,3.34)$

if $x_{1}$ is $(M, 348.90,1.11)$ and $x_{2}$ is $(M, 2.12,0.92)$ and $x_{3}$ is $A_{3,2}$ then $y$ is $(T, 14.99,3.34)$

if $x_{1}$ is $(M, 344.00,4.15)$ and $x_{2}$ is $(M, 2.15,0.80)$ and $x_{3}$ is $A_{3,2}$ then $y$ is $(T, 14.99,3.34)$

if $x_{1}$ is $(M, 355.08,3.86)$ and $x_{2}$ is $(M, 2.12,0.30)$ and $x_{3}$ is $A_{3,2}$ then $y$ is $(T, 24.18,3.34)$

if $x_{1}$ is $(M, 337.24,7.01)$ and $x_{2}$ is $(M, 2.15,0.80)$ and $x_{3}$ is $A_{3,2}$ then $y$ is $(T, 27.08,3.34)$

if $x_{1}$ is $(M, 358.46,11.99)$ and $x_{2}$ is $(M, 1.61,0.39)$ and $x_{3}$ is $A_{3,2}$ then $y$ is $(T, 30.84,3.34)$

Fig. 4. Knowledge base of the model of pressure courses in diesel engine fuelled by diesel oil

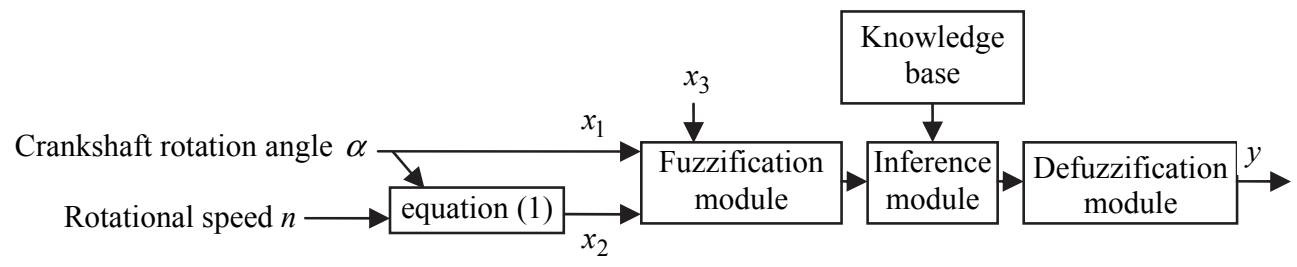

Fig. 5. Operation of the Mamdani-type fuzzy model of pressure courses, which has three input variables, $x_{1}, x_{2}$, and $x_{3}$, and one output variable, $y$

The time of computation of cylinder pressure curves and injection pressure curves for all tested rotational speeds (and time of writing of the results to disk) is less than $20 \mathrm{~ms}$.

\subsection{Extension of the model for other fuels}

The model that was built for diesel oil (Fig. 5) can be extended for the prediction of pressure curves in the engine fuelled by other mineral fuels. In order to achieve this, two scaling 
functions were added to the existing model (fuzzy system), one for the inputs and another for the output of the system (Fig. 6).

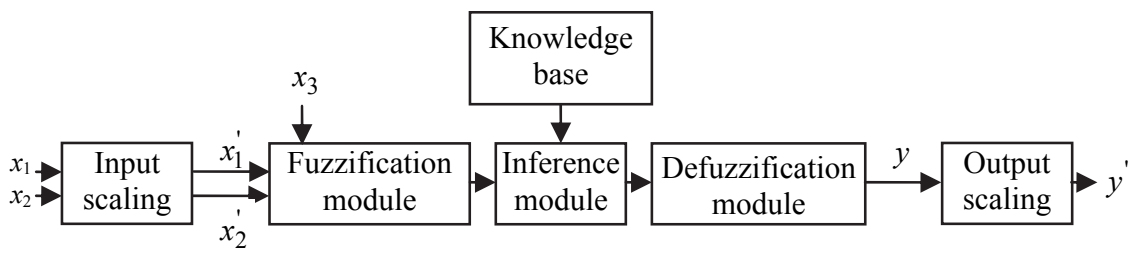

Fig. 6. Operation of the Mamdani-type fuzzy model of pressure courses, with scaling functions The output scaling function has 4 parameters: $a_{0}, a_{1}, a_{2}$, and $a_{3}$ :

$$
y^{\prime}=\left\{\begin{array}{r}
y \cdot \frac{a_{2}}{a_{0}} \text { for } y<a_{0} \\
\left(y-a_{0}\right) \cdot \frac{a_{3}-a_{2}}{a_{1}-a_{0}}+a_{2} \text { for } y \geq a_{0}
\end{array}\right.
$$

The input scaling function has only one parameter, $a_{4}$ :

$$
x_{1}^{\prime}=x_{1}-a_{4}
$$

The $x_{2}^{\prime}$ value is calculated as in Eq. 1, but using the $\alpha=x_{1}^{\prime}$ instead of $\alpha=x_{1}$. The values of parameters of output scaling function are calculated according to Table 1. Except for $\mathrm{a}_{0}$ and $a_{3}$, parameter values are different for each fuel. In order to obtain these values for a new fuel, it is necessary to measure the pressure curve as a function of crankshaft angle for only one rotational speed, for example, $1800 \mathrm{rpm}$.

Let $\alpha_{p_{c \max }}$ denote $\alpha$ value for which $p_{c}$ reaches its maximum value, $p_{c \max }$. Let $\frac{d^{2} p_{c}}{d \alpha^{2}}$ denote the second derivative of $p_{c}$ with respect to $\alpha$. For a certain value of $\alpha$, the $\frac{d^{2} p_{c}}{d \alpha^{2}}$ reaches its maximum, denoted $\left(\frac{d^{2} p_{c}}{d \alpha^{2}}\right)_{\max }$. The $p_{c}$ value at this point is the value of $a_{0}$ parameter when we consider cylinder pressure for diesel oil (see Table 1).

Analogically, we define $p_{i \max }$ and $\left(\frac{d^{2} p_{i}}{d \alpha^{2}}\right)_{\min }$, but we does not search the global minimum, but only the minimum in the range where $\alpha \in\left\langle 330, \alpha_{p_{\text {imax }}}\right\rangle$.

When $x_{3}$ is injection pressure, the $a_{0}=a_{2}$, and these parameters can be considered as the estimation of injector opening pressure.

Once the output scaling function has been determined, and when $x_{3}$ is injection pressure, the $a_{4}$ value is chosen for a new fuel in such a way that the root mean square error (RMSE) between the experimental and computational $p_{i}$ curves for rotational speed of $1800 \mathrm{rpm}$ is minimal 


$$
R M S E=\sqrt{\frac{\sum_{i=1}^{N}\left(y_{1, i}-y_{2, i}\right)^{2}}{N}}
$$

where $y_{1, i}$ and $y_{2, i}$ are experimental and computational values of $p_{i}$, respectively.

When $x_{3}$ is cylinder pressure, we select $a_{4}$ in other way, by choosing a value for which the mean indicated pressure (Rychter \& Teodorczyk, 2006) is calculated with the highest accuracy.

\begin{tabular}{|c|c|c|c|c|}
\hline $\begin{array}{l}\text { Para- } \\
\text { meter }\end{array}$ & \multicolumn{2}{|c|}{ Value (when $x_{3}$ is cylinder pressure) } & \multicolumn{2}{|c|}{ Value (when $x_{3}$ is injection pressure) } \\
\hline$a_{0}$ & \multirow{2}{*}{$p_{c}$ for $\alpha$ when $\left(\frac{d^{2} p_{c}}{d \alpha^{2}}\right)_{\max }$} & for diesel oil & \multirow{2}{*}{$\begin{array}{c}p_{i} \text { for } \alpha \text { when }\left(\frac{d^{2} p_{i}}{d \alpha^{2}}\right)_{\min } \\
\left(\text { for } \alpha \in\left\langle 330, \alpha_{p_{\text {max }}}\right\rangle\right)\end{array}$} & for diesel oil \\
\hline$a_{2}$ & & $\begin{array}{l}\text { for a new fuel } \\
\text { (e.g. RME) }\end{array}$ & & for diesel oil \\
\hline$a_{1}$ & \multirow{2}{*}{$p_{c \max }$} & for diesel oil & \multirow{2}{*}{$p_{i \max }$} & for diesel oil \\
\hline$a_{3}$ & & $\begin{array}{l}\text { for a new fuel } \\
\text { (e.g. RME) }\end{array}$ & & $\begin{array}{l}\text { for a new fuel } \\
\text { (e.g. RME) }\end{array}$ \\
\hline
\end{tabular}

Table 1. Values of parameters of the output scaling function

The Figs 7 and 8 present the way of calculation $(7 \mathrm{ab}, 8 \mathrm{ab})$ and application $(7 \mathrm{~cd}, 8 \mathrm{~cd})$ of output scaling function parameters.

\subsection{Accuracy of the model}

The accuracy of the model for RME fuel is presented in Table 2 (injection pressure) and Table 3 (cylinder pressure). The maximum pressure in injection pipe is predicted with error not exceeding $7.2 \%$, and the area below this pressure curve - with the error not exceeding $8.2 \%$ for any tested rotational speed. The maximum cylinder pressure error does not exceed $3 \%$, and mean indicated pressure is calculated with error not exceeding $8.1 \%$.

The model allows prediction of the pressure curves (Fig. 9) with accuracy required in practical applications.

\begin{tabular}{|c|c|c|c|c|c|c|}
\hline \multirow{2}{*}{\begin{tabular}{|l|} 
Rotational \\
speed, \\
$n$, \\
rpm
\end{tabular}} & \multicolumn{3}{|c|}{$\begin{array}{l}\text { Area } S \text { below the curve } \\
p_{i}=f(\alpha), \mathrm{MPa} \cdot{ }^{\circ} \mathrm{CA}\end{array}$} & \multicolumn{3}{|c|}{ Maximum pressure $p_{i \max }, \mathrm{MPa}$} \\
\hline & experimental & computed & $\delta S, \%$ & experimental & computed & $\delta p_{i \max }, \%$ \\
\hline 1000 & 382 & 366 & -4.1 & 20.6 & 20.3 & -1.4 \\
\hline 1200 & 394 & 386 & -2.1 & 21.1 & 21.8 & 3.3 \\
\hline 1400 & 418 & 424 & 1.5 & 24.7 & 26.5 & 7.2 \\
\hline 1600 & 440 & 442 & 0.3 & 28.0 & 28.4 & 1.2 \\
\hline 1800 & 461 & 449 & -2.7 & 30.6 & 30.1 & -1.6 \\
\hline 2000 & 492 & 452 & -8.2 & 32.6 & 31.0 & -4.9 \\
\hline
\end{tabular}

Table 2. Accuracy of the pressure curves model of a diesel engine fuelled by RME; comparison of the area below the injection pressure curve and the maximum pressure in the injection pipe 
(a)

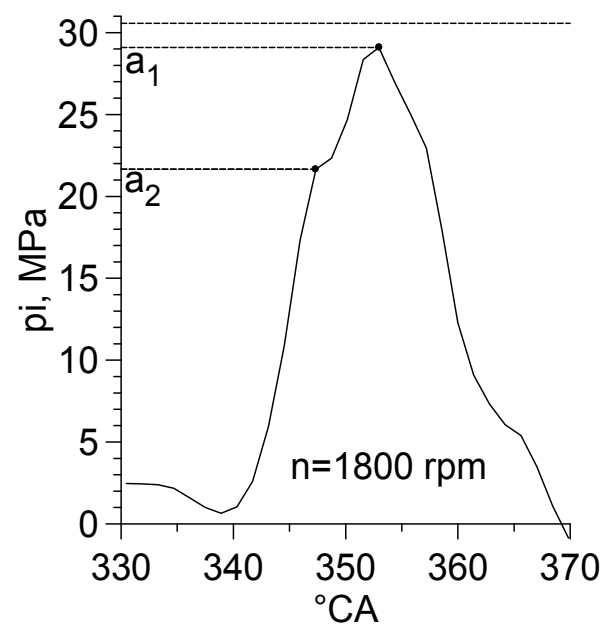

(c)

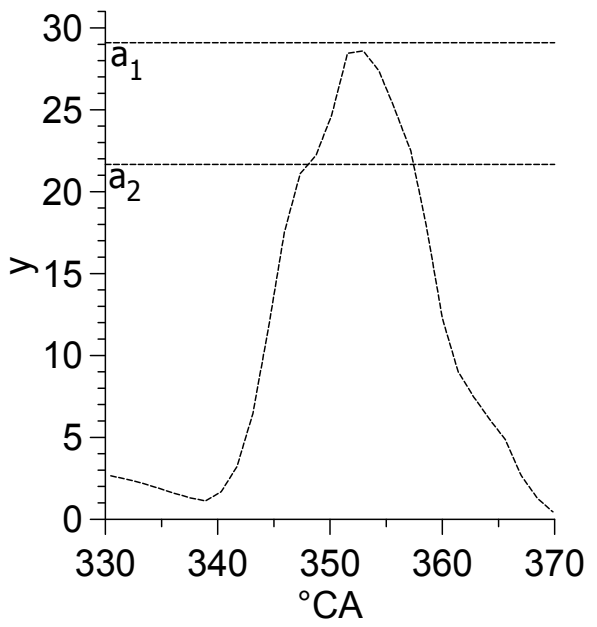

(b)

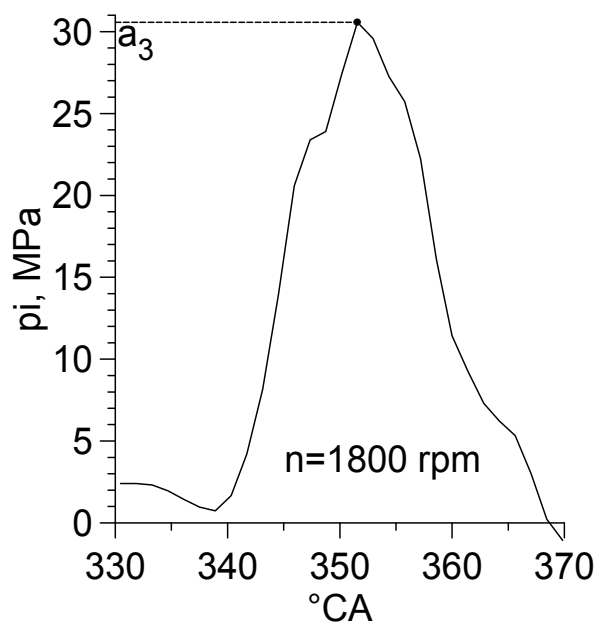

(d)

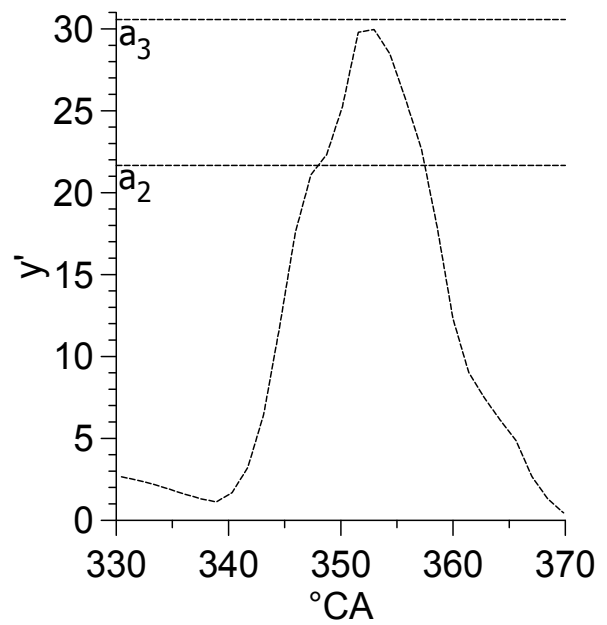

Fig. 7. Calculation and application of parameters of the output scaling function when $x_{3}$ is injection pressure: a) the experimental pressure curve $p_{i}$ and calculation of $a_{1}$, and $a_{2}=a_{0}$, when the engine is operated at a crankshaft speed of $1800 \mathrm{rpm}$ and fuelled by diesel oil; $b$ ) the experimental pressure curve $p_{i}$ and calculation of $a_{3}$ when the engine is operated at 1800 rpm and fuelled by a new fuel (for instance, RME); c) the pressure curve $p_{i}$ modelled without output scaling (for diesel oil) for a given rotational speed; $\mathrm{d}$ ) the pressure curve $p_{i}$ modelled with output scaling (for a new fuel, for instance, RME) for a given rotational speed 
(a)

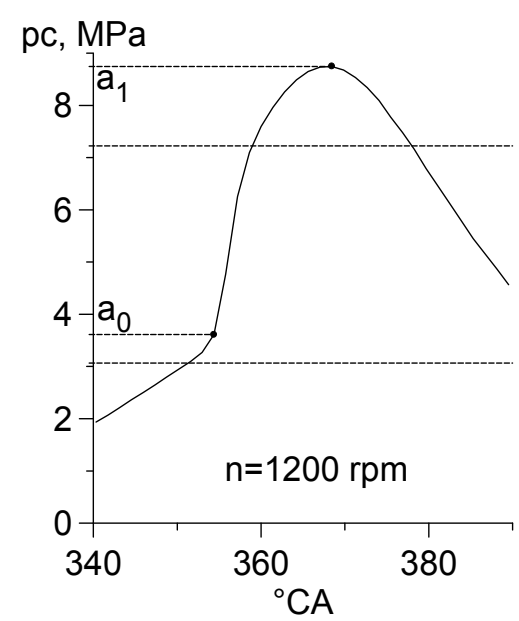

(c)

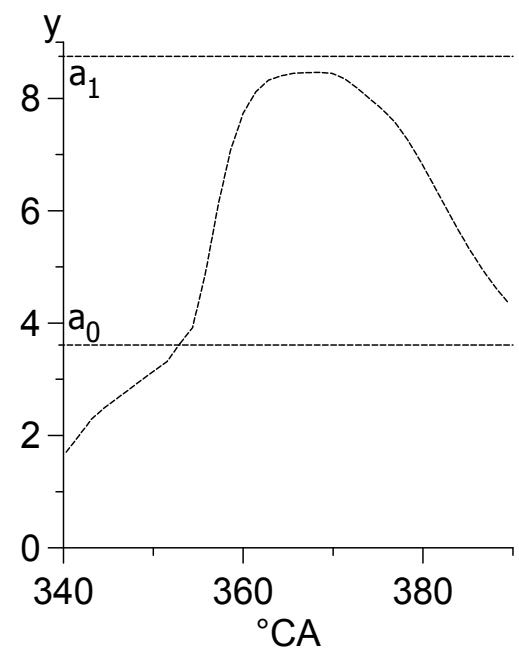

(b)

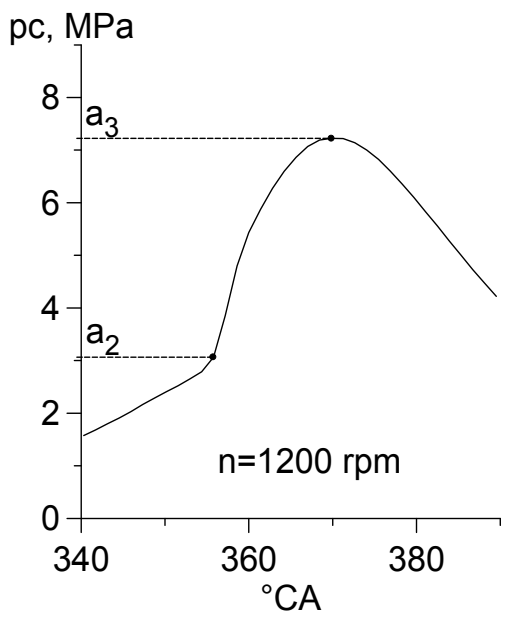

(d)

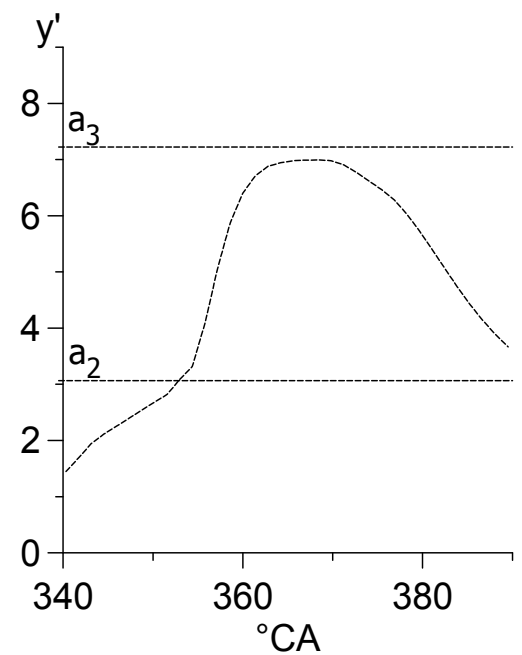

Fig. 8. Calculation and application of parameters of the output scaling function when $x_{3}$ is cylinder pressure: a) experimental pressure curve $p_{c}$ and calculation of $a_{0}$ and $a_{1}$ when the engine is operated at a crankshaft speed of $1200 \mathrm{rpm}$ and fuelled by diesel oil;

b) experimental pressure curve $p_{c}$ and calculation of $a_{2}$ and $a_{3}$ when the engine is operated at $1200 \mathrm{rpm}$ and fuelled by a new fuel (e.g., RME); c) the pressure curve $p_{c}$ modelled without output scaling (for diesel oil) for a given rotational speed; $d$ ) the pressure curve $p_{c}$ modelled with output scaling (for a new fuel, for instance, RME) for a given rotational speed 


\begin{tabular}{|c|c|c|c|c|c|l|}
\hline \multirow{2}{*}{$\begin{array}{l}\text { Rotational } \\
\text { speed, } n, \\
\text { rpm }\end{array}$} & \multicolumn{3}{|l|}{ Mean indicated pressure $P$} & \multicolumn{3}{l|}{ Maximum pressure $p_{c \max }, \mathrm{MPa}$} \\
\cline { 2 - 7 } & experimental & computed & $\delta P, \%$ & experimental & computed & $\delta p_{c \text { max }}, \%$ \\
\hline 1000 & 0.95 & 0.96 & 1,2 & 8.41 & 8.15 & -3.1 \\
\hline 1200 & 1.03 & 1.03 & $-0,2$ & 8.47 & 8.20 & -3.2 \\
\hline 1400 & 1.05 & 1.01 & $-4,1$ & 8.40 & 8.22 & -2.2 \\
\hline 1600 & 1.07 & 1.00 & $-7,1$ & 8.39 & 8.15 & -2.9 \\
\hline 1800 & 1.08 & 0.99 & $-8,1$ & 8.22 & 8.02 & -2.3 \\
\hline 2000 & 1.08 & 1.01 & $-6,8$ & 8.01 & 7.85 & -2.0 \\
\hline
\end{tabular}

Table 3. Accuracy of the pressure curves model of a diesel engine fuelled by RME; comparison of the mean indicated pressure (based on cylinder pressure curve) and the maximum cylinder pressure
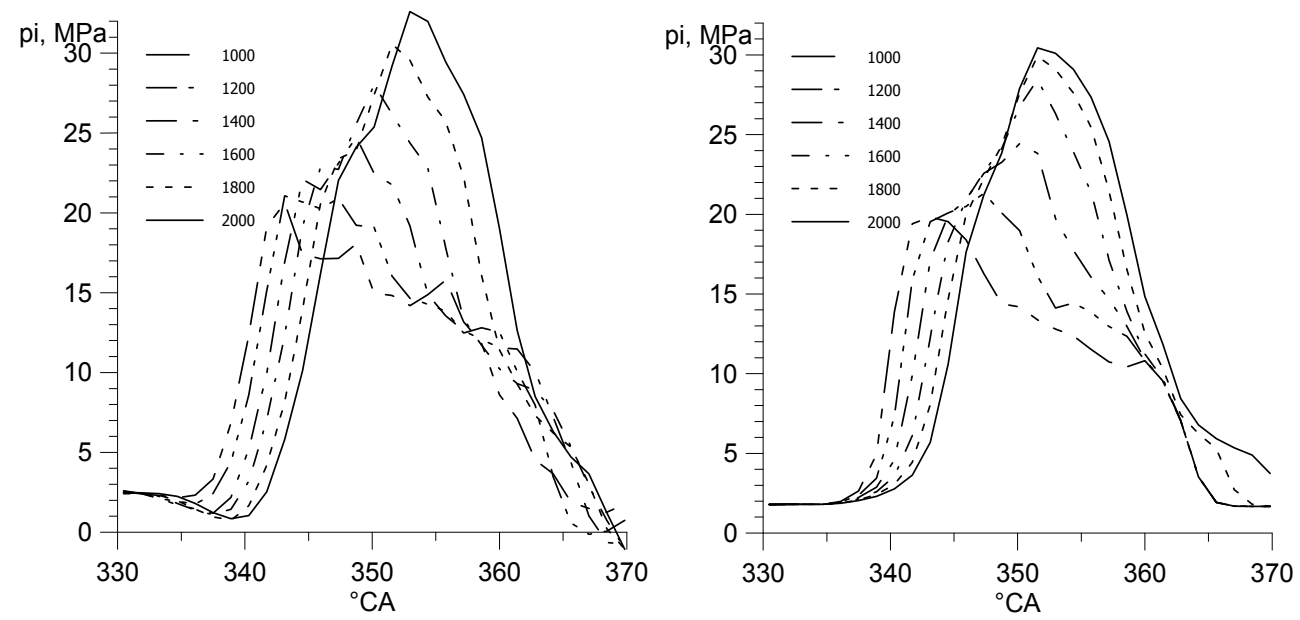

Fig. 9. The curves of injection pressure in function of crankshaft angle in the engine fuelled by RME at rotational speeds of 1000, 1200, 1400, 1600, 1800 and $2000 \mathrm{rpm}$ : (a) experimental, (b) computed by the model obtained in the GFSm system

\subsection{Comparison with models built by Fuzzy Logic Toolbox (FLT) and SANN}

In this section we compare only the models regarding pressure in injection pipe when engine was fuelled by diesel oil. The GFSm model regarding cylinder pressure was discussed in (Radziszewski \& Kekez, 2010). The model of injection pressure build by GFSm software was later transferred into Matlab Fuzzy Logic Toolbox (FLT) software in order to compare time of computation of the pressure curve by GFSm software and FLT software. Some new models of injection pressure were created using this Toolbox. Two of them are fuzzy models and one is a neuro-fuzzy model. We also used SANN (Statistica Automated Neural Networks) to automatically find the architecture of neural network and learning algorithm which produces the best model of pressure in injection pipe. The main disadvantage of the neural network model is the lack of its interpretability. The accuracy of modelling and time of computations for all models were compared. 


\subsubsection{Transfer of the model into FLT}

It was necessary to write the code of the function that implements Center Average Defuzzification method with minor modifications used by the GFSm model (Kekez, 2008). The accuracy of the model transferred into FTL depends on the number of points, $k$, for which the value of the membership function of the aggregated output fuzzy set was calculated. For $k=401$ points, the accuracy of original model (GFSm) and the same model implemented in FLT was identical, but FLT made all calculations in $80 \mathrm{~ms}$.

\subsubsection{Fuzzy models in FLT}

Attempts to build a new model of injection pressure using the FLT were carried out, using the same training dataset as used for GFSm (but without cylinder pressure data). The two models were built, using genfis3 function of the software: Takagi-Sugeno-type (Fig. 10a) and Mamdani-type (Fig. 10b). The first one has unsatisfactory accuracy, but the latter computed

(a)

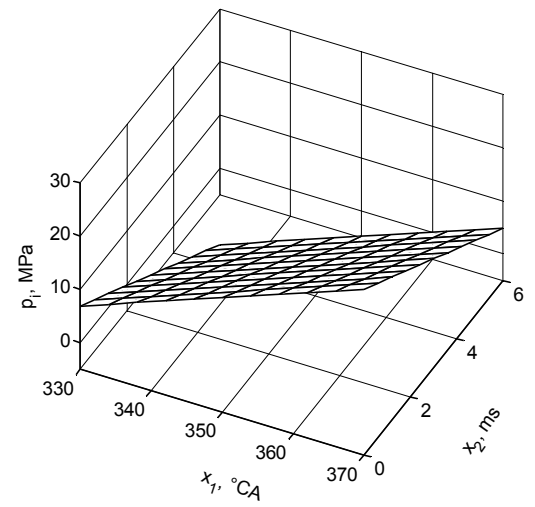

(b)

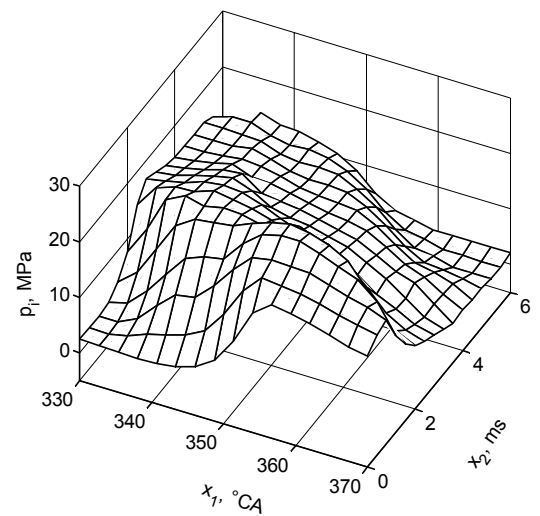

Fig. 10. Models of pressure in the injection pipe built by using the FLT function genfis3: a) Takagi-Sugeno-type, b) Mamdani-type 
the area below the curve (for $n=1200 \mathrm{rpm}$ ) with $4.3 \%$ error and the maximum pressure with $0.9 \%$ error. However, for other rotational speeds the accuracy of prediction of the maximum pressure was worse (errors up to $21.6 \%$ for $2000 \mathrm{rpm}$ ). Better accuracy could be achieved by checking other possible values of settings for the fuzzy c-means clustering procedure, or by changing the structure of training dataset.

\subsubsection{Neuro-fuzzy model in FLT}

We built the injection pressure model, using anfis function in FLT software, which implements neuro-fuzzy ANFIS method (Jang, 1993). In comparison with GFSm model (Table 4), the model built by ANFIS with default settings had slightly better accuracy of prediction of the area below the pressure curve for the speed of $1800 \mathrm{rpm}$, but over $60 \%$ error for $1000 \mathrm{rpm}$ (as compared to $4 \%$ in case of GFSm). Other settings of ANFIS parameters (model no. 2 in Table 4) resulted in very high accuracy for the speeds that were represented in the training dataset $(0.05 \%$ error) and very low accuracy for some rotational speeds $(225 \%$ error for $1000 \mathrm{rpm})$. This model was over-fitted to the training data. Better results could be achieved by checking other possible values of ANFIS settings, or by changing the structure of training dataset.

\begin{tabular}{|l|l|l|l|}
\hline$n,[\mathrm{rpm}]$ & GFSm & ANFIS default model & ANFIS model no. 2 (64 rules) \\
\hline & \multicolumn{2}{|l|}{ Error of calculation of the area below the pressure curve, \% } \\
\hline 1000 & -4 & -61 & 225 \\
\hline 1200 & -1 & 2 & 0 \\
\hline 1400 & 4 & 18 & -10 \\
\hline 1600 & 5 & 17 & -7 \\
\hline 1800 & 1 & 2 & 0 \\
\hline 2000 & -4 & 18 & -31 \\
\hline & Error of calculation of the maximum pressure, \% \\
\hline 1000 & -6 & -19 & 763 \\
\hline 1200 & -1 & -1 & 0 \\
\hline 1800 & -2 & -4 & 0 \\
\hline 2000 & -5 & -10 & 2 \\
\hline
\end{tabular}

Table 4. Comparison of accuracy of GFSm model and two ANFIS models for a diesel engine fuelled by diesel oil

\subsubsection{Neural-network models built by Statistica Automated Neural Network}

Neural networks have ability to approximate any non-linear function (Korbicz et al., 1994). Because the value of pressure is non-linearly dependent on crankshaft angle and rotational speed, we used neural networks for modelling this relation. Our choice was the STATISTICA Automated Neural Networks (SANN) software package. SANN builds many neural networks, i.e. tests all possible combinations of the following elements: network structure (including the number of neurons in hidden layer), activation function, and learning algorithm. This allows to avoid a situation where one neural network, a priori chosen by the researcher, poorly describes given non-linear relation. 
The SANN software was run with the following settings:

- analysis type: regression,

- sampling method: default (random selection, train $70 \%$, test $15 \%$, validation $15 \%$ ),

- network type: multi-layer perceptron (MLP), number of neurons in a hidden layer: default (minimum 2, maximum 8),

- $\quad$ activation functions in hidden layer and output layer: linear, logistic, tanh (hyperbolic tangent), exponential,

- create 1000 different neural networks and save the 5 best networks.

The learning dataset was almost the same as for GFSm system, but contained injection pressure data for the rotational speeds of 1200 and $1800 \mathrm{rpm}$.

After the creation of the networks, the best one (in terms of prediction accuracy of maximum pressure) was chosen from five networks saved by SANN software. This network had: 9 neurons in a hidden layer, logistic activation function in hidden layer and output layer. It was trained using BFGS (Broyden-Fletcher-Goldfarb-Shanno) algorithm with SOS (Sum Of Squares) error function, and the best solution was found in 145 th iteration. Accuracy of modeling of pressure course by this network is presented in Table 5 and Fig. 11.

\begin{tabular}{|c|l|l|l|l|l|l|}
\hline $\begin{array}{l}\text { Rotational } \\
\text { speed, } \\
n, \mathrm{rpm}\end{array}$ & \multicolumn{2}{l}{$\begin{array}{l}\text { Area } S \text { below the curve } \\
p_{i}=f(\alpha), \mathrm{MPa} \cdot{ }^{\circ} \mathrm{CA}\end{array}$} & \multicolumn{2}{l|}{ Maximum pressure $p_{i \max }, \mathrm{MPa}$} \\
\cline { 2 - 7 } & experimental & computed & $\delta S, \%$ & experimental & computed & $\delta p_{i \max }, \%$ \\
\hline 1000 & 381 & 358 & -6.0 & 21.3 & 21.0 & -1.5 \\
\hline 1200 & 392 & 390 & -0.3 & 21.3 & 21.2 & -0.6 \\
\hline 1400 & 406 & 415 & 2.2 & 24.2 & 24.5 & 1.1 \\
\hline 1600 & 417 & 431 & 3.3 & 26.4 & 26.9 & 2.0 \\
\hline 1800 & 439 & 441 & 0.4 & 29.1 & 28.1 & -3.6 \\
\hline 2000 & 462 & 448 & -2.9 & 30.9 & 28.6 & -7.7 \\
\hline
\end{tabular}

Table 5. Accuracy of injection pressure model, created by SANN

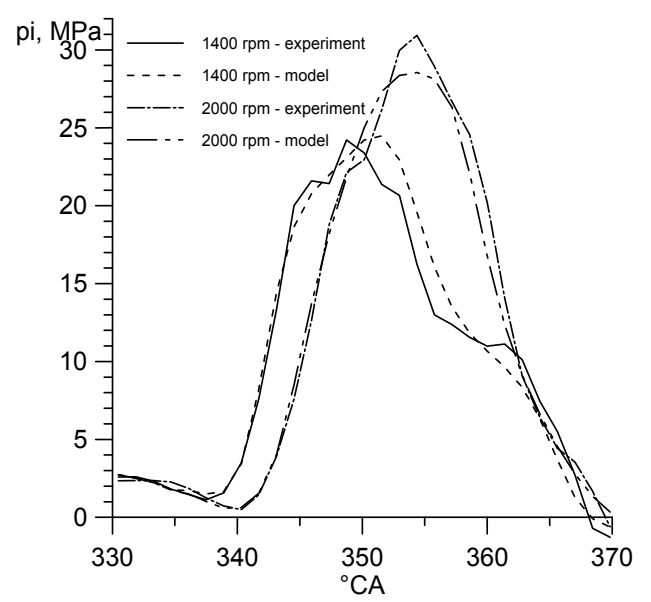

Fig. 11. Comparison of injection pressure model built by SANN software with experimental 


\section{Conclusion}

The single model of pressures in a diesel engine (in cylinder and injection pipe), created by GFSm system was presented. The model was built for diesel oil and extended for biofuels, using scaling functions. The obtained model can be applied to diagnostic and control of a diesel engine. One of the advantages of the proposed method is that the model was built for a one given engine and therefore describes its work with good accuracy, sufficient for most technical applications. The time of computation of cylinder pressure curves and injection pressure curves for all tested rotational speeds (and time of writing of the results to disk) is less than $20 \mathrm{~ms}$. Accuracy of the proposed model is better than accuracy of one neuro-fuzzy and one fuzzy model and slightly better than that of a neural network.

\section{References}

Abonyi, J., Babuska, R., \& Seifert, F. (2002). Modified Gath-Geva Fuzzy Clustering for Identification of Takagi-Sugeno Fuzzy Models. IEEE Trans. on Systems, Man and Cybernetics, Vol. 32, (2002), pp. 612-621

Ambrozik, A., Ambrozik, T., Kurczyński, D. \& Łagowski, P. (2010). Examination of fastchanging quantities in engine with common rail injection system. J. of KONES Powertrain and Transport, 2010, Vol. 17, No. 3, pp. 17-24, ISSN 1231-4005

Amsden, A. A. (1997). KIVA-3V: A Block-Structured KIVA Program for Engines with Vertical or Canted Valves. Los Alamos National Laboratory, LA-13313-MS

Cordon, O., Herrera, F., Hoffman, F. \& Magdalena L. (2001). Genetic Fuzzy Systems: Evolutionary Tuning and Learning of Fuzzy Knowledge Bases (Advances in Fuzzy Systems - Applications and Theory 19), World Scientific, Singapore

Holland, J. H. (1976). Adaptation, In: Progress in Theoretical Biology IV, R. Rosen, F. M. Snell, (Ed.), pp. 263-293, Academic Press

Jang, J. S. R. (1993). ANFIS: Adaptive-Network-Based Fuzzy Inference Systems, IEEE Transactions on Systems, Man, and Cybernetics, Vol. 23, No. 3, (1993), pp. 665-685

Kalogirou, S. A. (2003). Artificial intelligence for the modeling and control of combustion processes: a review. Progress in Energy and Combustion Science, Vol. 29, No. 6, (2003), pp. 515-566, ISSN 0360-1285

Kekez, M. (2008). Modelowanie pracy silnika o zaptonie samoczynnym z wykorzystaniem metod sztucznej inteligencji (in Polish), Kielce University of Technology, Ph.D. thesis

Korbicz J., Obuchowicz A., Uciński D.: Sztuczne sieci neuronowe. Podstawy i zastosowania (in Polish), Akademicka Oficyna Wydawnicza PLJ, Warszawa, 1994

Radziszewski, L. \& Kekez, M. (2010). Application of a genetic-fuzzy system to diesel engine pressure modeling. The International Journal of Advanced Manufacturing Technology, Vol. 46, No. 1-4, (2010), pp. 1-9, DOI 10.1007/s00170-009-2080-1

Regattieri Delgado, M., Von Zuben, F. \& Gomide, F. (2004). Coevolutionary genetic fuzzy systems: a hierarchical collaborative approach, Fuzzy Sets and Systems, Vol. 141, No.1, (January 2004), pp. 89-106, ISSN 0165-0114

Rychter, T. \& Teodorczyk, A. (2006). Teoria silników tłokowych (in Polish), Wydawnictwa Komunikacji i Łączności, ISBN 978-83-206-1630-1, Warszawa, Poland

Smith, S. F. (1983). Flexible learning of problem solving heuristics through adaptive search, Proceedings of Eighth International Joint Conference on Artificial Intelligence, pp. 422425, Karlsruhe, Germany, August 1983, Morgan Kaufman 
Wang, L. X. \& Mendel, J.M. (1992). Generating fuzzy rules by learning from examples. IEEE Trans. on Systems, Man and Cybernetics, Vol. 22, No. 6, (1992), pp. 1414-1427 


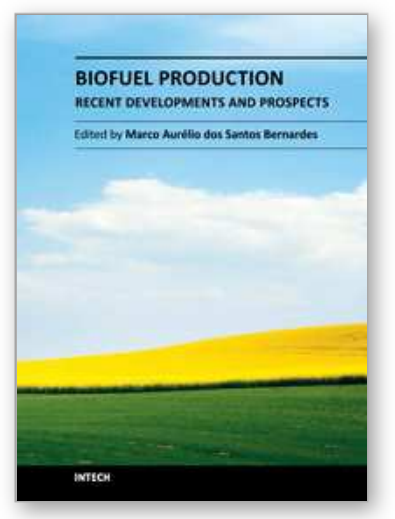

\section{Biofuel Production-Recent Developments and Prospects \\ Edited by Dr. Marco Aurelio Dos Santos Bernardes}

ISBN 978-953-307-478-8

Hard cover, 596 pages

Publisher InTech

Published online 15, September, 2011

Published in print edition September, 2011

This book aspires to be a comprehensive summary of current biofuels issues and thereby contribute to the understanding of this important topic. Readers will find themes including biofuels development efforts, their implications for the food industry, current and future biofuels crops, the successful Brazilian ethanol program, insights of the first, second, third and fourth biofuel generations, advanced biofuel production techniques, related waste treatment, emissions and environmental impacts, water consumption, produced allergens and toxins. Additionally, the biofuel policy discussion is expected to be continuing in the foreseeable future and the reading of the biofuels features dealt with in this book, are recommended for anyone interested in understanding this diverse and developing theme.

\section{How to reference}

In order to correctly reference this scholarly work, feel free to copy and paste the following:

Michał Kekez and Leszek Radziszewski (2011). A Genetic-Fuzzy System for Modelling of Selected Processes in Diesel Engine Fuelled by Biofuels, Biofuel Production-Recent Developments and Prospects, Dr. Marco Aurelio Dos Santos Bernardes (Ed.), ISBN: 978-953-307-478-8, InTech, Available from: http://www.intechopen.com/books/biofuel-production-recent-developments-and-prospects/a-genetic-fuzzysystem-for-modelling-of-selected-processes-in-diesel-engine-fuelled-by-biofuels

\section{INTECH}

open science | open minds

\author{
InTech Europe \\ University Campus STeP Ri \\ Slavka Krautzeka 83/A \\ 51000 Rijeka, Croatia \\ Phone: +385 (51) 770447 \\ Fax: +385 (51) 686166 \\ www.intechopen.com
}

\author{
InTech China \\ Unit 405, Office Block, Hotel Equatorial Shanghai \\ No.65, Yan An Road (West), Shanghai, 200040, China \\ 中国上海市延安西路65号上海国际贵都大饭店办公楼405单元 \\ Phone: +86-21-62489820 \\ Fax: +86-21-62489821
}


(C) 2011 The Author(s). Licensee IntechOpen. This chapter is distributed under the terms of the Creative Commons Attribution-NonCommercialShareAlike-3.0 License, which permits use, distribution and reproduction for non-commercial purposes, provided the original is properly cited and derivative works building on this content are distributed under the same license. 